\title{
Nos limiares da visibilidade midiática: apontamentos sobre a cronossensologia
}

Rosamaria Luiza (Rose) de Melo Rocha*

\begin{abstract}
Resumo
O artigo foca as experiências sensiveis e a constituição sensórea consolidadas na atual cultura das midias, apresentando apontamentos conceituais que buscam consolidar um estatuto básico para a interpretação deste fenômeno. Sintetiza, ainda, algumas das linhas teóricoepistemológicas que vêm orientando análises de material televisual e iconográfico selecionados como base documental de nossas pesquisas sobre as chamadas "Imagens limiares".
\end{abstract}

Palavras-chave: mídia, imagem, temporalidade, sensibilidade.

\begin{abstract}
The article focuses sensible experiences related to media culture, presenting conceptual appointments that intends to consolidate a basic interpretative estate of this phenomenon. Also analysis some theories and epistemological principles of image's analysis on "Limiar Images" research project.
\end{abstract}

Key words: media, image, temporality, sensibility.

\footnotetext{
"Professora e Pesquisadora do Núcleo de Pesquisa "Comunicação e Práticas de Consumo" da ESPM/SP. Pós-doutorado em Ciências Sociais (PUC/SP). Doutorado em Ciências da Comunicação (ECA/USP).
} 


\section{A tevê ou o existencialismo midiático'}

Este artigo parte da postulação segundo a qual a tevê constituise como lugar cronossensológico efêmero, estabelecendo com o espectador diversos pactos de "sensibilização". Deriva daí a compreensão da linguagem televisiva como parte de um quadro de circularidade midiática e dando ainda margem a uma inusitada midiatização de experiências cotidianas. A hibridização mídia/cotidiano articula-se à constituição subjetiva do homem contemporâneo e ao modo com que vimos experimentando nossos sentidos e nossa sensibilidade.

Ao falar de uma "sensologia" midiática indico que esta comporta três modulações mais evidentes ou significativas para os termos deste estudo: a performance, o apelo emocional, a cacofonia. Em primeiro lugar, identifico na linguagem midiática um forte componente performático: reforço mimético, de um lado, e função ordenadora, de outro.

Penso, neste último caso, em um princípio de ordenação que antecede, digamos, a edição referendada em conteúdos. Lembro, aqui, do funcionamento das máquinas de aprisionar o carom (Machado, 1993), nas quais o efeito ordenador remete, já no momento de registro, às peculiaridades do aparato técnico, ao crivo previamente estabelecido

128 pela forma-câmera, pela lógica-câmera, pela ótica-câmera. Ordenar e punir, mostrar e banir, aproximar e afastar, iluminar e ocultar, estes parecem ser um dos motes desta formulação discursiva.

Em segundo lugar, caracterizo esta linguagem como sendo ancorada no apelo direto aos sentimentos ou, mais propriamente, às sensações. Localizo, neste apelo, a base fundante tanto da banalização da vida cotidiana (o domínio do "já-sentido", teorizado por autores como Mario Perniola) quanto da sua espetacularização, no desencadear de uma hiperexcitação ou mobilização corpórea, sensorial. Unem-se, pois, o arrebatamento, o entretenimento e a dispersão. $\mathrm{O}$ "contrato de intensidade" substitui o de "visibilidade".

Finalmente, aponto uma terceira modulação obtida através da veiculação de flagrantes e de registros amadores que, até onde posso perceber, tendem a se colocar em um nível diverso do fluxo televisivo tradicional, posto que, levando ao paroxismo a estratégia das câmaras escondidas, surpreendem-nos em nosso continuum voyeurístico. Encontramos, aqui, um certo princípio de cacofonia. Analiso, assim, uma linguagem em sua forma de aparecimento, considerando-a, por sua vez, inserida em um dado contexto social e cultural. A simbiose mídia e cotidiano é parte deste "lugar". 


\section{Fantasma real, real simulado}

"Quando o fantasma se torna real, o real vira fantasmagórico", escreve Günther Anders (1956), para quem a familiaridade com o mundo, por lentes televisivas, é apenas uma pseudo-familiaridade. E não haveria de ser diferente, continua nosso autor, submersos que estaríamos na ambigüidade do transmitido: fatos presentes/ausentes, reais/aparentes, lá e não-lá. Para Anders, habitamos um lugar cronológico mutante, o agora.

Em seus estudos sobre a simulação da imagem, Arlindo Machado (1993) propõe, com extrema pertinência, que as câmeras sejam analisadas como aparelhos de aprisionar o carom². Para Machado, a tendência a vivenciarmos os registros assim produzidos - o fantasmagórico de que fala Anders - como certificados de garantia do acontecido, revela

a lógica subjacente desta nossa sociedade permeada pelos aparelhos de "duplicação" do real, imersa num mar de signos audiovisuais que constituem para nós o atestado de realidade das coisas. Cada vez mais. nós tendemos a confundir o evento com a sua enunciação simbólica, ou melhor ainda, os próprios eventos não acontecem senão para sua circulação nos veículos de informação (Machado, 1993:236).

"Guiar é como filmar", escreve Virilio (1984), analisando a conversão do vivido em pura velocidade de visibilização. Filmar é ordenar, interpreta Machado, pois, "quando filmamos, não estamos apenas reproduzindo imagens e sons de forma inocente. mas introduzindo um princípio de ordem, um sentido sobre aquilo que abordamos." Os aparelhos de enunciação visual", diz Machado. "constituem para nós uma espécie de totem" (1993:238-239). Através deles criamos e damos vida a duplos de nós mesmos, convertendoos, por vezes, no real que realmente conta, posto que perpetuado. para usar a terminologia de Jameson (1994), em "imagem tangível".

\section{A anti-esfinge midiática: consuma-me e não me decifre}

Analisando as transformações da imagem e do olhar no século vinte. Jameson (1994:115-143) distingue, como recurso periodizante. diferentes etapas na teoria da visão. Voltando-se à pós-modernidade. nosso autor nota. no momento que se inicia em fins de setenta e chega aos nossos dias. o surgimento de uma ruptura decisiva, visto que "a reflexividade como tal se submerge na pura superabundância de imagens como em um novo elemento no qual respiramos como se fosse natural": 
os sujeitos humanos, já expostos ao bombardeio de até mil imagens por dia, vivem e consomem cultura de maneiras novas e diferentes. (...) já não há nenhuma distância crítica com relação à cultura das imagens (...). A nova situação (...) significa uma mais completa estetização da realidade que é também, ao mesmo tempo, uma visualização ou colocação em imagem mais completa dessa mesma realidade (Jameson, 1994:120).

Esta última situação, ou terceiro momento, caracterizaria hoje a visualidade. A própria imagem se cotidianiza, deslizando do campo da cultura para se tornar elemento natural constitutivo de nosso dia-a-dia. Para Jameson, o visual pode ser analisado como meio em si de sedução e interpelação. Se a tevê é um mercado de imagens é, também, uma imagem-mercado e um mercado de sensações: as imagens televisivas, como natureza de segundo grau, propiciam uma sorte de vinculação perceptiva na qual a sensologia engolfa a imagologia.

\section{Modos de ver, modos de sentir: aspectos da sensologia midiática}

Com esta observação, chego às idéias de Mario Perniola (1991) acerca

130 das peculiaridades do "modo de sentir" contemporâneo. Se nossa época assiste a uma mudança substantiva nas formas de sensibilidade e na experiência perceptiva, encontramos, na derivação um tanto saudosista de Perniola, a ainda assim instigante formulação do "já sentido", este que caracteriza o primado de uma sensologia da exaustão e da monotonia.

Não temos escolha, diz Perniola, tudo é perpassado pelo sentir, que adquire uma dimensão anômica. Assim como a estetização da sociedade desfigura o Estético, a socialização dos sentidos aniquila, pelo excesso, a percepção do mundo (dos objetos, das pessoas, dos acontecimentos) como algo que "está por sentir":

O que está por sentir pode ser sentido ou não; mas o já sentido só pode ser recalcado (...) o já sentido é uma espécie de sensologia que se constitui com base no modelo da ideologia e que partilha com esta a atribuição de processos psíquicos à vida coletiva: ela não assume no entanto o aspecto de um convite (...) mas de uma intimação" (Perniola, 1991:12-14).

O processo de sensibilização do mundo proposto por Perniola equivale pois à experimentação de um sentir desprovido de surpresa, a um sentir obrigatório. Esta sensologia do "falso sentir", análoga ao modelo da ideologia, 
"acompanhada por uma falsa consciência", está ao abrigo da suspeita, posto que "é impossível desmascará-la como falsa, porque não pretende ser portadora de nenhuma verdade" (Perniola, 1991:14).

Tendo po" base estas considerações, Perniola procura distinguir, em sua argumentação, um conceito bastante peculiar de midiacracia. Para tanto, opera o seguinte deslocamento de ênfase analítica: já não são os meios de comunicação a assumirem o comando da sensologia, mas, antes, limitam-se mais a obedecê-la, precipitando-se "numa incessante corrida para a difusão antecipada do já sentido" (1991:16).

Sensologia do falso absoluto, midiacracia fundada no poder da ameaça, o já sentido é, nos termos de Perniola, um quase poder, uma imposição da mediação, cotidiana e ininterrupta, "que antecipa, precede e até substitui o fato" (1991:16). A derivação sugerida por Perniola. privilegiando uma leitura política do "modo de sentir" contemporâneo, visa exprimir, até onde percebo, o que seria a obliteração da razão em um quadro onde a estetização do real coaduna-se a uma crise propriamente ética, marcada pelo "primado do sentir sobre o pensar e o agir" (1991:17).

Talvez já não seja oportuno falar-se em narcisismo, continua nosso autor, mas sim em especularismo, posto que o já sentido é experiência jogada para fora de nós, através da qual o mundo cheganos provado. A ruptura entre natureza e razão, segundo Perniola, conduz à reificação do homem.

Esta metáfora da petrificação leva nosso autor a propor a seguinte oscilação, experimentada pelo homem-coisa: um já sentido "quente", contestatório e fundamentalista, outro "frio", cínico ou performativo. O assassinato da individualidade, implícito em tal enfoque, intensifica ainda mais o pessimismo pernioliano: a estetização e a socialização do sentir, nutrindo ambições universalistas, esfacelam a um só tempo o lugar da cultura e o papel da intelectualidade.

\section{Espaço virtual, imagem pública: a cronossensologia}

Chegamos, neste ponto, a outra tese que me parece relevante na interpretação da atual configuração do universo midiático, qual seja. da sua constituição como esfera pública, ou melhor, como espaço público virtual de apresentação e encenação. Preciso, para desenvolver este raciocínio, recorrer novamente a Jameson, pois encontro. em um excerto de sua obra, uma das chaves que podem nos ajudar a caminhar nesta proposição, aperfeiçoando-a.

Comentando a estruturação dos jornais como se fossem seriados. a um só tempo ficcionais e reais. Jameson vislumbra aí a manifestação de um novo domínio da realidade das imagens, relacionado-o a modificações 
profundas na esfera pública. Este campo híbrido, que se constrói nos interstícios da narrativa e da factualidade, tende à autonomização, uma semiautonomização, como escreve Jameson:

[ele] paira acima da realidade, com a seguinte diferença histórica fundamental: no período clássico, a realidade persistia, independentemente da "esfera cultural" sentimental e romântica, enquanto hoje parece ter perdido essa modalidade de existência em separado (Jameson; 1991:283).

"Não passam de sombras, sombras projetadas na tela, e acreditamos nelas, sofremos, nos comovemos com elas, as vivemos como se tivessem uma existência real, um caráter". Assim se expressava, acerca do cinema, o cineasta Frank Capra, agora, ele próprio, um discurso-imagem que assisto em meu canal de tevê fechada. Estoque doméstico deste mundo de sombras, a tevê, tal como hoje a conhecemos, não parece nutrir-se propriamente de uma exclusiva exigência de fidedignidade. Pois, como sugeria o cineasta, o que nos move é a fé, a crença em nossa vitrine de espectros, que tomamos por verídicos.

Não há mais história, simplesmente uma duração pública, sentenciaria por sua vez Virilio $^{3}$, destilando com amargura o efeito "videográfico" da vida contemporânea, o vivenciar da tele-realidade, espaço de apresentação dos "lugare's de imagens" è não mais das "imagens dos lugares" (Virilio, 1990:15). Em tempos de desagregação dos fatos, escreve Virilio, o único veículo percebido como eficaz é a imagem.

Proponho, na abordagem dos aparelhos de enunciação audiovisual, particularmente do meio televisivo, defini-los não exatamente como "espaço público" mas sim como "tempo público", "lugar" a uma s6́ vez cronológico e sensológico, cronossensologia midiática com estratégias próprias de visibilização/invisibilização. Seguindo este raciocínio penso identificar, neste campo de aparecimento e de encenação, a mesma sensação da "pequena morte", o mesmo "morrer um pouco" que Virilio associaria à experiência do viajante automotivo.

Sentimos intensamente o momento temporal veloz da presentação televisiva, sobrepondo-se à materialidade do écran a materialidade de segundo grau das imagens. Estas, por sua vez, são imagens que passam, que se movimentam diante de nossos olhos e, no momento seguinte, já "ficaram para trás", já abandonaram nosso campo de visão, inscrevendo-se, daí para frente, no campo das "imagens imaginadas", da subjetiva rememoração do visto. Esta, certamente, não 
é uma rememoração qualquer, posto que fruída em uma situação perceptiva peculiar: de um lado, a paralisia física do espectador - como a de um passageiro de trem ou de um motorista -; de outro, a movimentação incessante e fragmentária das imagens.

No "lugar" midiático sentimos o tempo mas, também, "temporalizamos" as sensações e, por suposto, as imagens. Oscila-se entre a territorialização - as imagens fixadas, espacializadas, conformadas ao tempo televiso - e a desterritorialização - as imagens se dispersando na velocidade de aparecimento, o referente, o "real" eclipsado na velocidade intensiva, experimentado através da mediação técnica em detrimento das informações obtidas diretamente através dos sentidos. A intensidade do visto, a interpelação visual convida os espectadores ao mergulho na tela mas, também, pode distanciá-los ou, como escreve Jameson, abstraí-los de seus contextos sociais imediatos (Jameson, 1994:137).

Televiajantes que hoje somos, experimentamos, diante do écran televisivo, o movimento ininterrupto e intensivo de múltiplas partidas e chegadas. Mal a vimos já nos despedimos de uma imagem, embarcamos em outra e assim sucessivamente. Afinal, o zapping, prática que um autor como Machado (1993:143-164) corretamente interpretaria como fundamentalmente ambígua ${ }^{4}$, já foi reapropriado por sua linguagem-mãe. a tevê, e, todos sabem, usado com fluência pelo telejornalismo.

\section{A mídia como "caixa de reverberação"}

Se a linguagem televisiva opera com base em uma estrutura fragmentária, dispersa, oscilante, como analisar seu possível impacto unificador, como caracterizar a generalização cultural deste dialeto compartimentado, taxativo e repetitivo? Uma das respostas a este problema pode ser encontrada se nos detivermos na análise formulada por Deleuze e Guattari a propósito da segmentaridade. Este estudo revela que somos segmentarizados binariamente, circularmente e linearmente, sendo que tais figuras "passam umas nas outras, transformando-se de acordo com o ponto de vista". "A vida moderna", dizem eles, "não destituiu a segmentaridade". Mas. em suma, "a endureceu singularmente" (Deleuze e Guattari, 1980:84).

Para perceber a dimensão deste endurecimento, consideremos o que os autores nos dizem acerca da mutação da segmentaridade circular, comparando-se as sociedades ditas primitivas e as modernas:

A segmentaridade torna-se dura, na medida em que todos os centros ressoam, todos os buracos negros caem num ponto de acumulação - 
como num ponto de cruzamento em algum lugar atrás de todos os olhos. O rosto do pai, do professor primário, do coronel, do patrão se põem a redundar, remetendo a um centro de significância que percorre os diversos círculos e repassa todos os segmentos: As microcabeças flexíveis, as rostificações animais são substituídas por um macro-rosto cujo centro está por toda parte e a circunferência em parte alguma. Não se tem mais $n$ olhos no céu ou nos devires vegetais e animais, mas sim um olho central computador que varre todos os raios (Deleuze e Guattari, 1980:87).

A organização da ressonância à qual se referem, e da qual o Estado seria o principal aparelho, leva-me à seguinte proposição. Nas sociedades midiáticas ou, para usar a terminologia de Perniola, nas midiacracias, cabe aos meios de comunicação, já sintonizados com a cultura tecnológica, a função de "caixas de reverberação" das imagens-acontecimentos, das imagens-pessoas, das imagenssensações, das imagens-estilos-de-vida e assim por diante.

Ao se defrontarem com esta segmentaridade molar, endurecida, com as máquinas abstratas de sobrecodificação, Deleuze e Guattari notam entretanto que, em uma de suas manifestações,

quanto mais a organização molar é forte, mais ela própria suscita uma molecularização de seus elementos, suas relações e seus aparelhos elementares. Quando a máquina torna-se planetária ou cósmica, os agenciamentos têm uma tendência cada vez maior a se miniaturizar e a tornar-se microagenciamentos (Deleuze e Guattari, 1980:93).

Assim, se a mídia é lugar cronossensológico molar, ponto de acumulação sujeito ao princípio da inércia, tal endurecimento não exclui a molecularização; ao contrário, dela depende. Mas o efeito "cronossensológico", ou videográfico, confere aos micro-fragmentos audiovisuais uma característica de uniformidade, visto que todos, ao caírem nestas zonas de acumulação, mergulham igualmente na circularidade midiática, passam pelo crivo de sua linguagem tautista, aculturam-se no poder ordenador desta que é, igualmente, uma potência disjuntiva.

É esta a linguagem que faz os micro-fragmentos ressioarem em conjunto, submetendo-os a um envelhecimento precoce, a um déjà-vu do, por vezes, jamais visto ${ }^{5}$. Paradoxo do "morrer" para aparecer, (con)fusão representar/expressar, é também esta, por vezes, o escoadouro de nosso sentir possível, de nossa aproximação possível — posto que 
mediada - com mundos outros, os quais, porventura, já não possamos experimentar.

\section{Os contratos de sensibilização}

Tendo por base as observações acima registradas, estar-se-ia, ao que parece, diante de variados "contratos de visibilidade". Procurase ora por uma ordenação, ora é-se surpreendido por uma sensação de hiper-realismo, como se a tela se tornasse mais real do que o real, como se ele, já não tendo mais força, cedesse lugar à sensibilização imagética, à violência hiper-realizada, doravante a que nos "cativaria". É sintomático que grande parte destas imagens que causam horror ou indignação sejam feitas por cinegrafistas amadores.

Analisando a imagem televisual, Vernier propõe classificá-la a partir de três ordens, cada qual com um específico contrato de visibilidade 6 , "implicando em uma certa forma de crença, de adesão, um julgamento daquilo que se mostra, visando um telespectador ideal e prevendo um modo específico de relação deste com as imagens" (Vernier, 1988:10). Na primeira ordem, da "imagem-profundidade", o contrato visa a credibilidade das imagens, conferindo-lhes um caráter tátil, na remissão ao que seria uma "infância da televisão", quando se tomavam as coisas como de fato seriam, na presunção de uma objetividade pura.

Na segunda ordem, da "imagem-superfície", o contrato é o do espetáculo, baseado na necessidade e na primazia da mise-en-scène. Progressivamente, escreve Vernier, são os fragmentos de imagem que se dão a ver, conduzindo-nos à terceira ordem, da "imagem-fragmento". Nesta, o contrato de visibilidade é energético, pulsante, pura sensação. "Para o telespectador o mundo não é mais do que uma colagem de imagens, combinatório de intensidades visuais" (Vernier, 1988:10-16).

Creio que os contratos de visibilidade passam, hoje, pelo princípio da "confusão". Parece-me que a convenção em torno do que se deseja visibilizar torna-se extremamente fluida. O limite do olhar, na oscilação entre as três ordens, sendo que a última tende a engolfar as demais, conduz-nos a um estado de suspense ininterrupto: imaginamos ver o real, e o que vemos é sua encenação; pensamos desfrutar de um teatro, quando, na verdade, o que se vê é real; em outros casos, gostaríamos que o real fosse uma encenação. Movimento ambíguo que, colocando em relevo, em mobilização incessante e fracionada a capacidade perceptiva, não possibilita que se saiba ao certo o que de fato nos aguarda e, menos ainda, o que será capaz de nos chocar. Parodiando Virilio, em sua referência ao "tempo de duração" das imagens, sugiro que pensemos, na análise destas imagens televisuais. 
em termos de "tempos de sensibilização". Talvez, neste caso, o que esteja em jogo seja o que pode ser sentido e não mais o que pode ser visto.

Jacques Aumont (1990), em seu estudo sobre as imagens visuais, dedica, por seu turno, um tópico às interseções entre a imagem e as pulsões do espectador ${ }^{7}$. Retomando as origens do termo, nos fundamentos da psicanálise freudiana, Aumont chega a Lacan, descrevendo as bases interpretativas da chamada pulsão escópica. Esta implica "a necessidade de ver e o desejo de olhar", olhar que "emana do sujeito perceptivo de modo ativo e mais ou menos deliberado", sujeito que, por sua vez, está imerso em um complexo jogo de imagens, uma vez que ver é também o "vendo-se ver-se" (Aumont, 1990:125).

Prosseguindo em seu mapeamento dos fundamentos psicanalíticos dos estudos do olhar, Aumont aborda a temática do voyeurismo, tocando, finalmente, no que seria "o gozo da imagem", aspecto discutido no clássico trabalho de Roland Barthes (Barthes, 1980) sobre a fotografia, particularmente em sua noção de punctum.

Nesta apreensão da imagem, o espectador, por meio de associações subjetivas, descobre na foto um objeto parcial de desejo, satisfação de sua pulsão escópica, visto que esta foto "permite ver (uma realidade posta em cena) mas também olhar (o fotográfico no estado puro, que provoca o espectador - o punctum, diz Barthes, é também o que aponta - e o faz gozar da foto)" (Aumont, 1990:127-8).

\section{Lipovetsky e o "consumo emocional": a cômoda comoção}

Voltando-nos para o estado de "encantamento" ambíguo, a um só tempo fugaz e intensivo, disjuntivo e ordenador, que caracteriza a cronossensologia midiática, damo-nos conta de que há outra nuance que não pode ser esquecida. O "lugar cronossensológico" é também aquele no qual exercita-se a comoção.

Segundo a desencantada leitura de Lipovetsky, a comoção com o sofrimento alheio, sob o crivo midiático, assume uma feição verdadeiramente desprezível. Somos acometidos de uma "generosidade circunstancial", diz o autor, fantasia de interação e compromisso na qual a própria tristeza é motivo de entretenimento, cenário virtual onde circulam os arautos de uma ética de terceiro tipo, de uma "teatralidade do Bem", encenação altruísta que se presta ao "consumo individualista emocional" (Lipovetsky, 1992:154-7).

Agora, os grandes temas, as grandes preocupações são ditadas 
pelo que Lipovetsky chama de "golpes midiáticos". No exercício desta "moral sentimentalo-midiática", comprazemo-nos de partilhar imaginária e pontualmente da infelicidade do outro; somos, até mesmo, "tocados" por este espetáculo de "identificação epidérmica". Não seremos julgados, não seremos culpabilizados. Seremos sensibilizados:

O altruísmo do pós-dever compraz-se com a distância: tornamo-nos mais sensíveis à miséria exposta no pequeno écran do que à que nos é imediatamente tangível, há maior comiseração pelo outro distante do que pelo que nos está quotidianamente próximo. (...) Se o neoindividualismo significa desculpabilização do egoísmo, faz-se acompanhar, ao mesmo tempo, de uma maior participação imaginária e pontual na infelicidade do outro, sem que esta piedade resulte, todavia, em atos exemplares (Lipovetsky, 1992:159-160).

Verdade parcial, eu diria, visto que, em alguns casos, o aparecer midiático, o registro televisivo, é o que atesta a existência de eventos e pessoas. Aqui, é o "outro próximo" que só se torna real quando transfigurado em seu duplo, tal como observado por Machado (1993). É o caso da violência policial que grassa na periferia e que, após ser veiculada em emissoras de tevê, aterroriza moradores da região e de locais semelhantes, como se, a partir da divulgação de práticas constitutivas de seu cotidiano, se tornassem reféns de seus próprios "fantasmas".

"Parece um teatro, mas não é...", alertava um tanto constrangida a repórter do então telejornal sensacionalista "Cidade Alerta" ao documentar, em meio a um batalhão de festivas crianças, acenando e macaqueando para a câmera, a cena de um crime na periferia de São Paulo que resultara na demorada exposição em via pública de três cadáveres rijos e ensangüentados. Seu semblante tenso contrastava com a profusão de bocas sorridentes. que, na ânsia de se mostrarem, desconheciam a um só tempo repórter e cadáveres. A atração ali estava no olho da câmera. A morte, o assassínio, simples passaporte para o "ser visto", o choque de julgamento entre o que se considera banal e espetacular. As crianças eram duplamente ruidosas.

Perversão do desvelamento, exploração da banalidade, neste contexto também a politica de informação passa por uma metamorfose, e a mídia pode tomar parte de um processo de inquisição social generalizado (Virilio, 1976:235). Nas tevês, o medo e a insegurança sobrepõem-se às informações, partilhando de uma estratégia de "higiene" moral e social: equilíbrio sanitário. 


\section{Notas}

${ }^{1}$ Este artigo apresenta resultados parciais da pesquisa "Imagens limiares e visualidades juvenis", desenvolvida, desde setembro de 2004, junto ao Núcleo de Pesquisa "Comunicação e Práticas de Consumo" da ESPM/SP. Dialoga, ainda, com resultados de nossas pesquisas de doutorado e pós-doutorado, ambas financiadas pela Fapesp.

2 "Em língua jê, carom é o nome que os índios canelas apaniecras do Maranhão dão às imagens e às vozes das pessoas e das coisas, sejam elas atuais dos vivos ou virtuais dos mortos que retornam sob a forma de fantasmas" (Machado, 1993:235).

${ }^{3}$ Citando Charles Péguy.

4 " Há ambiguidade (...) embutida no gesto do zapper. De um lado, ele pode obter, com o frenesi de seu controle remoto, objetos singulares, ainda que efêmeros (...). Ao mesmo tempo, na contramão de seu percurso, ele também torna sensível uma certa homogeneidade estrutural básica das imagens e dos sons da televisão" (Machado, 1993:146).

${ }^{5}$ A existência de aparelhos de ressonância, escrevem Deleuze e Guattari, não significa a eliminação das segmentações finas, a proliferação, digamos, extramuros de focos moleculares, destes que operam nos detalhes, potência micropolítica esquadrinhadora, "fissura em zigue-zague". De uma parte, as linhas de fuga, de outra, as linhas de destruição.

6 "Por contrato de visibilidade entendemos uma sorte de convenção que se

138 estabelece entre o medium TV e o público sobre a natureza do que é dado a ver, em outros termos é uma relação construída pelo dispositivo televisual da enunciação"(Vernier, 1988:10).

${ }^{7}$ Contrariando as orientações de Eco, em seu já clássico Como se faz uma tese, utilizo-me do mapeamento de Aumont em vez de recorrer às citações dos textos originais. Tal postura foi adotada, neste caso, devido à consideração do valor analítico e igualmente didático da leitura realizada por Aumont. Creio que esta síntese é suficiente aos propósitos das reflexões que ora desenvolvo.

\section{Referências}

ANDERS, Günther (1956). Die Antiquiertheit des Menschen (I). Munique, Beck, 1994. (Trad. Ciro Marcondes Filho).

AUMONT, Jacques (1990). A imagem. Campinas, Papirus, 1993.

BARTHES, Roland (1980). A câmara clara. Rio de Janeiro, Nova Fronteira, 1984.

DELEUZE, Gilles e GUATTARI, Félix (1980). "Micropolítica e segmentaridade". In: Mil Platôs. Capitalismo e esquizofrenia, Vol. 3. Rio de Janeiro, Editora 34, 1996, pp. 83-115. 
JAMESON, Fredric (1989). "Introdução". In: As marcas do visível. Rio de Janeiro, Graal, 1995, pp. 1-6.

JAMESON, Fredric (1991). Pós-modernismo. A lógica cultural do capitalismo tardio. São Paulo, Ática, 1996.

JAMESON, Fredric (1994). "Transformações da imagem na pós-

modernidade". In: Espaço e imagem. Teorias do pós-moderno e outros ensaios. Rio de Janeiro, Editora UFRJ, 1994, pp. 115-143.

LIPOVETSKY, Gilles (1992). O crepúsculo do dever: a ética indolor dos novos tempos democráticos. Lisboa, Dom Quixote, 1994.

MACHADO, Arlindo (1993). Máquina e imaginário. O desafio das poéticas tecnológicas. São Paulo, Edusp, 1993.

PERNIOLA, Mario (1991). Do sentir. Lisboa, Presença, 1993.

VERNIER, Jean-Marc (1988). "Trois ordres de l'image télévisuelle". Quaderni, $\mathrm{n}^{\circ} 4$, primavera de 1988. Paris, CREDAP, Université Paris Dauphine, pp. 9-18.

VIRILIO, Paul (1976). L'insecurité du territoire. Paris, Galilée, 1993.

VIRILIO, Paul (1984). L'horizon négatif. Paris, Galilée, 1984.

VIRILIO, Paul (1996). "'A century of hyper-violence'. Paul Virilio: an interview". Economy and Society, volume 25, n 1, fevereiro de 1996. pp. $11-126$. 
CONTRACAMPO 13 